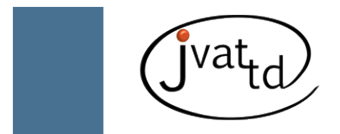

\title{
Clinical and immunological aspects of envenomations by Bothrops snakes
}

Luna KPO (1, 2), da Silva MB (2), Pereira VRA (3)

(1) Department of Biology, University of Paraíba, Campina Grande, Paraíba State, Brazil; (2) Department of Biophysics, Federal University of Pernambuco, Recife, Pernambuco State, Brazil; (3) Aggeu Magalhães Research Center, Oswaldo Cruz Foundation, FIOCRUZ, Recife, Recife, Pernambuco State, Brazil.

\begin{abstract}
Accidents caused by snakes, especially in tropical and subtropical countries, still constitute a serious public health problem due to the lack of knowledge of health professionals and the precariousness of health systems in the regions where most accidents occur. Snake venoms contain a range of molecules that may provoke local swelling, pain, renal and respiratory insufficiencies. The study of the effects of each molecule on humans can help the development of complementary therapy. Similarly, the knowledge of clinical aspects of envenomations provides a better identification and implementation of appropriate treatment. In addition, to understand Bothrops envenomations and improve the therapeutic strategy, it is necessary to understand and study the role of important inflammatory mediators, particularly nitric oxide (NO), cytokines and the complement system.
\end{abstract}

Key words: snakes, envenomations, clinical aspects, immunology.

\section{INTRODUCTION}

Snakebites comprise an important neglected public health problem that affects people worldwide. This is particularly relevant in rural areas of tropical and subtropical countries, where the bites are more common and where the access to health services and antivenom is limited. The actual magnitude of the threat of snake envenomations to public health in several countries is unknown, which makes it difficult for the responsible institutions to optimize prevention and treatment (1).

A study was conducted aiming to estimate the reality of snakebites. Globally, 1.8 million people are annually envenomed, of which 94,000 die. Furthermore, India is the country where most envenomations occur $(81,000$ per year), followed by Sri Lanka $(33,000)$, Vietnam $(30,000)$, Mexico
$(28,000)$ and Nepal $(20,000)$. Brazil appears along with Vietnam, with approximately 30,000 accidents per year (1).

Recently, snakebites were introduced by the World Health Organization in the list of neglected tropical diseases (2). The Global Snake Bite Initiative (GSI) was formed to develop practical and sustainable solutions to some of the problems associated with snakebites worldwide, especially concerning the notification of accidents $(3,4)$. According to GSI, mortality associated with snake envenomations is greater than in Chagas disease, dengue, cholera, leishmaniasis and schistosomiasis. In Latin America, most snakebite is caused by species of the Bothrops genus (5). Bothrops snakes are responsible for $90.6 \%$ of the accidents reported in Brazil, with a lethality index of $0.45 \%$. Accidents often occur in the beginning or end of the year, affecting particularly male 
rural workers at the productive age (between 19 and 45 years), mostly in their lower limbs (6).

To understand this type of envenomation and improve the therapeutic strategy, besides clinical and epidemiological studies, it is necessary to understand the role of inflammatory mediators such as nitric oxide (NO), cytokines and the complement system. Several studies describe the involvement of cytokines in envenomations by snakes, scorpions and spiders (7-9). Nitric oxide also participates in the pathogenesis of snake envenomations by two different mechanisms: it may lead to tissue damage due to its ability to generate peroxynitrite and hydroxyl radicals after interaction with superoxide ions; and it may provoke hypotension by its vasodilator action $(10,11)$. The precise function of NO in snake envenomations has yet to be investigated, but it is probably important in systemic effects caused by snake envenomations (7). Moreover, the mechanism by which snake venoms induce the production of cytokines and NO is unknown (7). It has been observed that animals experimentally injected with Bothrops venoms showed leukocyte accumulation which is dependent on eicosanoid release and chemotactic factors derived from serum (12). However, the latter effect is probably due to the complement activation (13).

The study of clinical and immunological aspects of Bothrops envenomation would help us to understand the patient's evolution, aiming new therapies.

\section{VENOM}

Usually, the actions of snake venoms involve coagulopathy, thrombocytopenia, edema, inflammation, shock, intracranial hemorrhage, pituitary hemorrhage, renal failure, thrombosis and pulmonary embolism. These outcomes occur because snake venoms are complex biological mixtures - composed of proteins, nucleotides, and inorganic ions - used for immobilization and death of prey for food (14). Instant immobilization of preys is provoked by respiratory or cardiac failure. The venoms contain approximately $25 \%$ of solid weight, from which 70 to $90 \%$ are proteins and polypeptides of relative high molecular weight.

Coagulopathy, an effect triggered by numerous snake venoms, provokes reduction of blood coagulability; increased tendency to bleed; bleeding due to damaged veins; and progressive systemic side effects such as hemorrhage, shock, intracranial hemorrhage, pituitary hemorrhage, renal failure, thrombosis and pulmonary embolism (15). A range of components may activate the coagulation system, which does not necessarily result in thrombosis; actually, it results in consumption of coagulation factors, leading to the non-coagulability (15). Snake venoms can inhibit or activate platelets, as well as form an active surface for the coagulation cascade. In addition, thrombocytopenia may occur, which leads to an increased bleeding (16).

Some toxins, known as hemorrhagins, have between 55 and $105 \mathrm{kDa}$ and can act by degrading components of the basal lamina of vessels and promoting their disruption or producing direct lesion on endothelial cells $(17,18)$.

The first hemorrhagin isolated from snake venom was BAP-1 (a metalloproteinase), obtained from Bothrops asper and which causes inflammation (19). This class P-I hemorrhagin (snake venom metalloproteinase type I) is edematogenic when injected into mice paw. After intramuscular injection blisters and leukocyte infiltrate were observed on the dermis, which was associated with degranulation of mast cells and enlargement of macrophages $(20,21)$.

It has been showed that the main mediators of edema caused by $B$. jararaca venom are derivatives of the arachidonic acid. In addition, authors claim that serotonin is also involved in the development of paw edema in mice. The mechanism of edema formation differs from the mechanism of hemorrhage, since the arachidonic acid does not participate in local hemorrhage induced by this venom. Interestingly, animals pretreated with guanetidina, capsaicin or subjected to surgical denervation presented mild hemorrhage, but not edema. This suggests that hemorrhage and edema comprise multimediated phenomena (22).

Variable degrees of thrombocytopenia are commonly found in patients envenomed by Viperidae and by some species of Elapidae and Colubridae snakes (23). Whether or not thrombocytopenia is connected with spontaneous systemic bleeding depends on the venom involved, especially if platelets are inactivated as well as being depleted in numbers $(24,25)$. The combination of thrombocytopenia and prolonged clotting time has been reported to increase the risk of bleeding $(15,24)$. Results 
of platelet counts suggest that thrombocytopenia contributes to the development of systemic bleeding in Bothrops envenomation, as previously reported, and is generally correlated with the severity of envenomation (15). In addition to thrombocytopenia, impairment of platelet function is also observed in patients bitten by B. jararaca. The pathophysiology of platelet disorders is complex, but their association with coagulation disturbances and endothelial cell damage certainly contributes to the development of systemic bleeding (15, 24-29).

However, platelet count of patients envenomed by $B$. jararaca with systemic and/or local bleeding is rapidly normalized after antivenom therapy, reaching almost normal values six hours after antivenom infusion. Antivenom therapy alone was effective in restoring platelet count in affected patients, without the need of platelet replacement therapy (29). Such findings suggest that the augmentation in platelet count following venom neutralization by antivenom may be due to the dramatic production of interleukin-6, a potent promoter of thrombopoiesis and megakaryocytopoiesis (30-32). This has been observed in both experimental and human envenomations by some Bothrops venoms (7, 33-35). Sequestered platelets apparently do not account for the rapid increase in platelet counts observed in patients following antivenom therapy, as the return of sequestered platelets does not occur in rabbits experimentally injected with $B$. jararaca venom (25).

Blood platelets control the inflammation at several steps and may contribute to the extent of the hemorrhage and inflammatory processes induced by $B$. jararaca venom $(36,37)$. Thus, toxins responsible for thrombocytopenia might increase local swelling indirectly $(29,38)$.

Several Bothrops snake venoms may cause brain bleeding, such as those from caribean snakes. Thomas et al. (39) evaluated three patients bitten by Bothrops lanceolatus. The first patient, even though arrived at the hospital 45 minutes after the bite, presented coagulopathy and thrombocytopenia, and was treated with 20 $\mathrm{mL}$ of antivenom. Magnetic resonance imaging (MRI) showed acute bilateral infarction and, on this basis, the patient was diagnosed with a grade 4 envenomation and more $20 \mathrm{~mL}$ of antivenom was administered. Blood coagulation returned to normal in three days and the patient was discharged from the hospital.

The second patient showed what seemed to be a 'dry bite', he was subjected to tetanus prophylaxis measures and received $20 \mathrm{~mL}$ of antivenom (BothroFav ${ }^{\oplus}$, Aventis-Pasteur, France). Moreover, his neurological exams were normal. Although discharged on the same day from the hospital, on the next day the patient returned with acute ischemic stroke. Blood tests showed the occurrence of coagulopathy. Thus, the patient was treated with more $40 \mathrm{~mL}$ of antivenom.

The third patient was admitted to the hospital two hours after the bite and was treated with 20 $\mathrm{mL}$ of antivenom. Still, 24 hours after the accident, he presented thrombocytopenia. MRI revealed acute bilateral infarction, so he received more 40 $\mathrm{mL}$ of antivenom.

Finally, the authors observed that even though the patients received antivenom doses within the required time, two of them presented brain infarction. Therefore, they claim that the knowledge on the variability of venom composition may be important for the development of more effective antivenom against snakebites (39).

Similarly, Malbranque et al. (40) reported a case of a 74-year-old man who was bitten by a Bothrops lanceolatus snake. After two days of treatment with traditional medicine, the patient sought a hospital. Although blood coagulation was normal, the platelet count was low and $80 \mathrm{~mL}$ of BothroFav ${ }^{\otimes}$ was administered to the victim. Results of MRI were normal. Cerebral and myocardial infarctions were observed and the patient was declared dead after 10 days. The authors claim that $B$. lanceolatus and $B$. caribbaeus envenomation present activation of vascular endothelium, with release of immature forms of von Willebrand factor (vWF), expressing adherent surfaces for platelet agglutination by vascular endothelial growth factor (VEGF-type) (40).

Bothrops caribbaeus is another snake found in Central America, which also has thrombotic venom. Numeric et al. (41) reported for the first time a case of $B$. caribbaeus envenomation (country of Santa Lucia). In this case, the patient presented local pain and swelling limited to the affected leg six hours after the bite, when he received treatment. One week after the bite the patient showed left hemiplegia with left facial paralysis. MRI revealed multiple areas of cerebral 
ischemia, in addition, the patient presented bloody leakage at the site of the bite, extensive swelling of the right lower limb, and edema at the abdominal wall and upper chest. Necrosis was also observed at the bite site. After two months, released from the hospital, the patient presented neurological sequelae.

The authors argue that this envenomation developed signs and symptoms very similar to those developed in a B. lanceolatus envenomation case in Martinique. Phylogenetic studies suggest that the venoms of the two Caribbean species of Bothrops are very close and may have the same thrombogenic potential (41). So, monospecific antivenom for $B$. lanceolatus envenomations could be useful for the treatment of $B$. caribbaeus envenomations as well, since a non-specific one for the latter is available (42).

Bothrops envenomations cause rapid development of edema and inflammation at the bite site. The edema induced by these venoms are associated with the action of various substances such as: hemorragins (act directly on the endothelium of capillaries and small veins, increasing permeability), cytotoxins (induce the release of histamine, $\mathrm{PLA}_{2}$, and arachidonic acid, which frees membrane phospholipids, starting the synthesis of prostaglandins that, in turn, increases capillary permeability), proteases (break kininogen releasing kinins and leading to the production of nitric oxide and prostaglandins); vasoactive peptides (inhibit the action of the angiotensin converting enzyme and boost the action of bradykinin); and components of the complement cascade $(43,44)$.

Myonecrosis is also a common result of envenomations by Bothrops snakes. The venom affects muscle cells due to the action of myotoxins on ionic channels, which alters the permeability of the cell membrane, and because of the indirect action of proteases, which causes disruption of vessels leading to muscle cell ischemia (33). $B$. jaracussu presents the higher myotoxic activity among the Bothrops genus (45).

In addition, Bothrops toxins may provoke shock by activating hypotensive substances that trigger the kallikreins-kininogen-kinin system, increasing vascular permeability and facilitating circulation outside of vessels. In non-pathological states, the substances responsible for this activity are kinins (46).

The study of Bothrops jararaca venom led the Brazilian researchers Rocha e Silva et al. (47) to the discovery of bradykinin, which directed to the formulation of captopril, widely used in the treatment of hypertension, heart failure, congestive heart failure and coronary artery disease. Therefore, the study of venoms has provided the elucidation of various pharmacological mechanisms (47).

\section{PARTICIPATION OF CYTOKINES, NITRIC OXIDE AND COMPLEMENT SYSTEM}

Several studies describe the involvement of cytokines in envenomations by snakes, scorpions and spiders (7-9). Figure 1 shows the production and activation of mediators by snake venoms.

The pathogenesis of systemic effects of Bothrops envenomations is complex. The role of cytokines, $\mathrm{NO}$ and the complement system in the pathology of envenomations has been the subject of studies $(7,12,13,34)$.

It has been proven that individuals bitten by Bothrops jararaca and Crotalus durissus terrificus in Brazil showed increased levels of IL- 6 and IL-8. Theincrease of IL- 6 could explain thelymphopenia and leukocytosis, since this cytokine is able to increase the secretion of adrenocorticotropic hormones and glucocorticoids. This author suggests that snake envenomations resemble acute traumas, inducing a typical acute response (35).

It was found that subcutaneous injections of $B$. atrox venom (from Butantan Institute Serpentarium, SP, Brazil) in mice induced chronic inflammation and signs of plasma exudate, leukocyte migration and vascular damage that resulted in hemorrhage and disruption of skeletal muscle cells. This study revealed that IL- 6 was not produced by splenocytes; instead, IL-10 was expressed by splenocytes and peritoneal cells. Similarly, IFN- $\gamma$ was produced by peritoneal cells, not splenocytes. In addition, authors hypothesized the following: plasma exudation may be mediated by bradykinin local release and histamine; leukocyte migration and adhesion might be initiated by C3a, C5a and/or IL-8; endothelial cells can be activated and p-selectin (as well as e-selectin) expressed through paracrine activation by histamine, thrombin-like activity and TNF- $\alpha$; accumulation of basophils and leukocytes may be mediated by IL-8; and, finally, disruption of skeletal muscle cells can be driven directly by proteases 


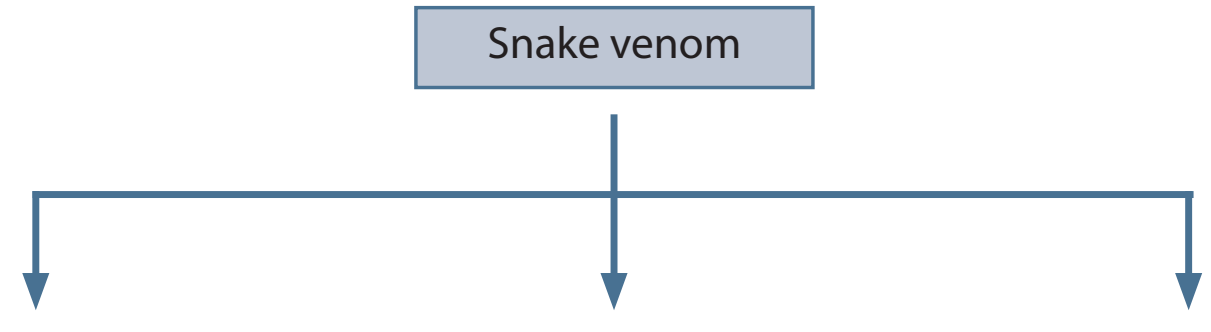

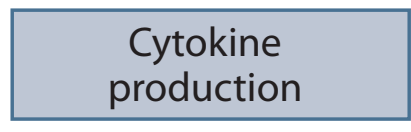

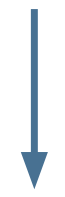

- IL-1; IL-6; IL-8; IFN- $;$; TNF- $\alpha$; mRNa expression directly in TNF- $\mathrm{a}$, IL-1 and IL-6 by macrophages (Jararagin-C)

- IIFN- - , TNF-a, IL-10, and IL-4 on human TCD4+
NO production

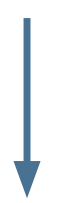

- Induction of tissue lesion according to its ability to generate nitrites and peroxynitrites

- Contributes for hypertension due to its vasodilatory properties

Figure 1. Production and activation of mediators by snake venoms.

as PLA $_{2}$, hemorrhagins or citolytic compounds present on venoms, or indirectly by mediators released by leukocytes (48).

Studies on B. asper and B. jararaca venoms (from the Serpentarium of Clodomiro Picado Institute, Costa Rica) showed that the seriousness of envenomations would probably be linked to high levels of IL-1, TNF- $\alpha$ and IL- 6 , while on moderate or mild envenomations, IL- 6 would show a moderate level, and IL- 1 and TNF- $\alpha$ were not increased. In their experiments, Petricevich et al. (7) showed the presence of IFN- $\gamma$ and IL-10 in envenomed mouse serum (7).

The effects of neutrophil depletion on cytokine expression, chemokines and inducible nitric oxide synthase (iNOS) induced by B. atrox venom (from the Butantan Institute Serpentarium) were studied with the objective of understanding tissue lesions caused by this venom. The results showed that neutrophil-depleted animals did not have significant neutrophil influx in the peritoneal cavity or the gastrocnemius muscle, compared to non-depleted animals. Levels of IL-6, MIP-1 $\beta$, MIP- 2 and NO, but not of IL- $1 \beta$, were significantly higher in serum of depleted animals. When mRNa of cytokines of depleted and non-depleted animals were analyzed, the authors concluded that IL-1 $\beta$, IL-6, iNOS, RANTES, MIP-2 and CXCR2 were detected in cells of both groups of mice; TNF- $\alpha$ and TGF- $\beta$ were not detected; and CCR1, CCR5 and MIP-1 $\beta$ were detected only in cells of depleted animals. These findings indicate that neutrophils negatively regulate the expression of MIP-1 $\beta$, CCR 1 and CCR 5 by cells of damaged tissue, which is important for cell migration on inflammation (48).

Clissa et al. (49), investigating the effects of jararhagin-C - a toxin composed only of disitegrin-type and cysteine-type domains - on the induction of leukocyte rolling and release of pro-inflammatory cytokines at the inoculation site, showed that jararhagin-C stimulated the interaction between leucocytes and post capillary veins, since the number of rolling leucocytes increased by $250 \%$ after treatment in vivo with the isolated toxin. In addition, the toxin was able to induce the release of cytokines such as IL- $1 \beta$, IL-6, and TNF- $\alpha$ (49).

The investigation on inflammatory properties of neuwiedase, a P-I class hemorrhagin isolated from Bothrops neuwiedi (subspecies B. n. goyazensis, B. n. meridionalis, B. $n$. paranaensis and B. n. urutu) was carried out by Xavier da Silva and Rodrigues (50). The study 
employed gastrocnemius cell cultures and showed that infiltrated cellular cultures treated with neuwiedase were composed mainly of polimorphonuclear cells in acute stages, then, in later stages, macrophages appeared (51). These results corroborate those of Fernandes et al. (52), who analyzed BAP-1 from B. asper. Jararhagin was also able to induce the accumulation of leucocytes in mouse air pouch. Regarding the release of cytokines induced by neuwiedase, Fernandes et al. (52) observed a significant increase in $\mathrm{KC}$ (chemokine similar to human IL-8) in muscle homogenate two hours after inoculation with neuwiedase. Significant increase of IL- 6 and IL-1 $\beta$ was also verified. This information agrees with studies on BAP-1, with the increase of IL- 6 and IL-1 muscular homogenate and increase in levels of IL- $1 \beta$ and peritoneal exudate of mice injected with the same hemorrhagin $(19,53)$.

It was observed that the increase in IL-1 would lead to augmented expression of IL-6 and IL- 8 (KC). IL-1 and IL-6 induced the expression of adhesion molecules by endothelial cells, i.e. induced leukocyte migration (54-56). The authors concluded that muscle can have an important role in inflammation induced by snake venom metalloproteinases (SVMPs), since it comprises the most important tissue responsible for the production of cytokines by neuwiedase $(50,54-56)$. The release of IL-1 and IL-6 after the injection of BAP-1 on muscle cells suggests that, in addition to mediate mast cell production, cytokines may also be involved in local inflammatory response induced by BAP1 (54). According to this hypothesis, increasing levels of IL-1 were observed in mouse peritoneal exudate after injection of BAP-1 (52).

Subsequent investigation showed that jararhagin stimulates directly $\mathrm{mRNa}$ expression of TNF- $\alpha$, IL- 1 and IL- 6 by macrophages (57). This suggests that macrophages are important SVMP targets. In a study with knockout mice, TNF- $\alpha$ and IL-6 receptors showed that both cytokines are relevant to the development of jararhagin-induced necrosis, but not edema or hemorrhage (58).

The mechanism by which Bothrops venoms induce cytokine production is not fully understood (7). In experiments with flow cytometry, Luna et al. (59) incubating mononuclear cells of human healthy individuals with $1 \mu \mathrm{g} / \mathrm{mL}$ of $B$. erythromelas venom (from northeastern Brazil), showed significant expression of IFN-g, TNF- $\alpha$,
IL-10, and IL- 4 on TCD $4{ }^{+}$cells, when compared to non-stimulated cell cultures through flow cytometry. These results indicate that the venom of that snake induces a $\mathrm{TH} 1 / \mathrm{TH} 2$ cell type response that activates $B$ cells, macrophages and dendritic cells involved in phagocytosis (60). This is especially important in inflammation processes in this type of envenomation, by cleaning necrotic tissue at the bite site.

Farsky et al. (61), investigating whether B. asper venom (from the Atlantic zone of Costa Rica) would have the ability to activate the complement system, showed that C5a is involved in leukocyte locomotion in the presence of the venom in vivo and in vitro. Additionally, the metalloproteinase $\mathrm{BaP}-1$, isolated from the same venom, was able to activate the complement system, which can be observed by the decrease in serum hemolytic activity. The authors also claim that BaP-1 activated the chemotaxis of neutrophils, which was not observed with any venom PLA $_{2}(61)$.

Lunaetal.(62)observed thatbothB.erythromelas and C. d. cascavella (from northeastern Brazil) venoms induced increased production of IFN- $\gamma$ and IL-6 in mouse splenocytes. Nitric oxide was produced in significant amounts only by $B$. erythromelas venom, which also showed a higher rate of cell death induction when compared to $C$. d. cascavella. Results showed that B. erythromelas and $C . d$. cascavella venoms induced a marked immunomodulatory response, in vitro, through cytokines and NO production. However, B. erythromelas induced pro-inflammatory response and a higher rate of cell death in relation to $C . d$. cascavella venom (62).

In order to assess to what extent the complement system would be involved in the pathogenesis of inflammation and/or hemorrhage, the Hi5 protein from $B$. atrox venom (Butantan Institute) was isolated and analyzed. It presented hemorrhagic activity and was capable of activating the complement system. When incubated with normal human serum, this hemorrhagin lost its hemolytic activity. This effect was dose-dependent and was accompanied by consumption of $\mathrm{C} 3$ and $\mathrm{C} 4$. In the same study, semipurified C3 was incubated with Hi5, and cleaved into smaller fragments. Hi5 protein was then injected into gastrocnemius mouse muscle, inducing inflammation characterized by edema and inflow of PMN. Hemorrhage was not changed. The authors also argued that, 
apparently, the complement system was a source of endogenous mediators of the primary effects of acute inflammation, such as C3a and C5a, and also participates in recruiting leukocytes, but not in the induction of hemorrhage (63).

Thus, studies involving the participation of the NO, cytokines and the complement system provide experimental evidence that the direct action of venom toxins in various tissues have a relevant role in the pathogenesis of systemic alterations characteristic of Bothrops envenomations.

\section{THERAPY}

At the beginning of the $19^{\text {th }}$ century, Vital Brazil (1865-1950) described, for the first time, a specific therapy for the treatment of envenomations caused by snakes. After reading a report of Calmette's anti-Naja serum, Vital Brazil purchased monovalent sera against the venoms of Bothrops jararaca and Crotalus durissus terrificus. In 1889, this led to the first demonstration of the specificity of anti-venomous serum and later to the first production of polyvalent serum for therapeutic use $(64,65)$. At that time, the scientist immunized horses with the venoms of Lachesis lanceolatus (currently Bothrops jararaca) and Crotalus terrificus (today Crotalus durissus terrificus). Since then, serum therapy was definitively introduced into clinical practice. In Brazil, the antivenom producers are Butantan Institute, Ezequiel Dias Foundation and Vital Brazil Institute $(66,67)$.

The antibodies used for efficient neutralization of venom toxins are specifically addressed to the toxins responsible for local and systemic actions. Generally, antivenom must be specific, except in cases of similar symptoms, such as accidents provoked by Lachesis and Bothrops snakes. Nevertheless, polyspecific antivenoms present disadvantages due to their low efficiency. On account of structural differences of each toxin, some may lead to the production of antibodies against the predominant toxins to the detriment of others. In addition, these toxins reduce the response of the immunized animal, consequently reducing the quantity of antibodies produced, due to the immunosuppressive activity of some venoms, such as C.d. terrificus and L. muta muta. Variability among species and individuals must also be considered, since there are variations among periods of time in the year, age of the specimen and geographic distribution (68).

Thus, to reduce problems with hypersensitivity some producers cleave the immunoglobulin molecule into their independent fragments, featuring as final product only the portion $\mathrm{F}(\mathrm{ab})_{2}{ }_{2}$ or Fab (68).

Several studies on genetic correlation of snakes within the same genera have been performed. The proteomic characterization of venoms contributes to a better understanding on biology, ecology and physiopathology of envenomations caused by these animals. Moreover, the knowledge of different families of toxins may be relevant for the creation of immunization protocols based on production of antibodies with greater specificity and effectiveness that conventional ones, produced in horses (69).

Luna et al. (62), who analyzed the humoral immune response presented by individuals bitten by the snake Bothrops erythromelas, showed a marked $31 \mathrm{kDa}$ protein that was not neutralized by the commercial antivenom used in Brazil. Such finding shows that some venom components are not well neutralized when the venom is not part of the pool of venoms used to generate the antivenom (62).

Nowadays, the understanding of molecular mechanisms that participate in venom variations, including ontogenetic and geographic characteristics, may lead to a great impact on the treatment of snakebite victims, as well as in the selection of specimens for the generation of improved antivenoms (69).

The inter- and intra-species heterogeneity in venom composition should be considered in symptoms of envenomation in humans, especially with regard to envenomation triggered by the same species in different geographic regions (70). Understanding the antigenic variation of toxins of snake venoms from different geographic origins can lead to the design of new therapeutic approaches, specific to each toxin, based on the immunogenicity of these components. Furthermore, more accentuated inter- and intraspecific variation may have an impact on the treatment of victims, and calls attention to the need of using a mixture of venoms for the production of more effective antivenoms. Thus, the development of specific antivenom is related to detailed knowledge of venom composition and the immunological profile established by each one (71). 
A good example of antivenomics (the identification of venom proteins that are recognized by an antivenom using proteomic techniques) is the case of the genus Crotalus (71). The antivenom produced against Crotalus simus simus venom, a Central American species, is ineffective in neutralizing the neurotoxicity of Crotalus durissus terrificus venom from South America. Likewise, antivenoms produced in South America against C. d. terrificus venom are ineffective in neutralizing the hemorrhagic activity of other venoms of the Crotalus genus. This case illustrates how the knowledge of variations on snake venoms and their geographic distribution can lead to the creation of more effective antivenoms against the venoms of Crotalus in South and Central America (70).

One of the most studied species in terms of proteomics, with respect to individual, geographic and ontogenetic variations of its venom is $B$. asper, the most medically important snake from southern Mexico to southern Central America (72). Recently its venom was characterized on a molecular basis as well as the ontogenetic changes in its composition. Notably, a similarity of $52 \%$ was indentified among the venom of $B$. asper populations from the Caribbean and Pacific regions (72).

Alape-Giron et al. (72) reported that B. asper snakes from the Caribean and Pacific regions present different venom protein profiles, which could be employed to identify the origin of the animals. The geographic variability of venoms reported by the authors points out a possible impact on the treatment of snakebite victims and the selection of specimens for antivenom production. This study shows the importance of using pooled venoms for antivenom production (72).

Important ontogenetic variations were identified in venom pool of neonate and adult snakes of the species $B$. asper from the same geographic region (Caribbean and Pacific). The largest variations were observed in ontogenetic shift in SVMP SVMPs-PIII-PI, and secretion of $\mathrm{PLA}_{2}$ in adults, but in small amounts in newborns. Furthermore, this ontogenetic resulted in increased complexity of the venom, indicating that a change in the venom regarding restraining and digesting the prey is related to snake age (72). Intraspecific diversity resulting in clinical variability of envenomations must be considered since bites by specific populations may require different treatments (73).
Lomonte et al. (73) evaluated the venom of $B$. atrox from Colombia, Brazil, Peru and Ecuador, and showed that Colombian and Brazilian snake venoms share a few toxins, including batroxastatin, a BPP, two K49- and one D49$\mathrm{PLA}_{2}$, a CRISP, and a LAO. These venoms also revealed different proteins that may be useful as regional markers.

The same authors analyzed the Costa Rican antivenom against the snake venoms obtained from the four countries and showed that the antivenom neutralized $100 \%$ of the Ecuador venom. In the case of Brazil and Peru, more than $90 \%$ of the venoms were neutralized. This cross reactivity profile evidences the close evolutionary kinship between B. asper and B. atrox (73).

Polyspecific commercial antivenoms produced in horses that were subjected to additional venom injections presented a higher neutralizing activity compared with antivenoms prepared with plasma of horses subjected to only one immunization. Hence, the authors indicate repeated immunization cycles to increase the neutralizing potency of the hyperimmune plasma (74).

The isolation of a large number of toxins specific to immunization requires access to large amounts of venom, which is not always possible. Alternatively, the structural information of a specific toxin from the venom may facilitate the cloning and expression of particularly important venom toxins (74). Another alternative is that immunization with DNA specific to a particular toxin or chimeric DNA which, together with a drawing of the molecule through bioinformatics, can predict whether the molecule is immunogenic enough to stimulate antibody production (75-77).

Therefore, complementary approaches related to the discovery of molecules that neutralize a variety of venom toxins are essential to reach advances in treating snake envenomation.

\section{CONCLUSIONS}

It is important to understand the global burden of snakebites, since it comprises one of the neglected tropical diseases according to WHO (2). The involvement of society, politicians and researchers is necessary to improve educational, research and political actions, aiming to diminish envenomations provoked by snakes throughout the globe. 
Hence, studies on mediators of the immune response such as NO, cytokines and complement system are necessary in order to clarify the role played by them in the evolution and emergence of clinical manifestations of patients envenomed by Bothrops snakes, enabling new advances in preventive strategies and immunochemotherapy (at regional and global levels).

\section{COPYRIGHT}

(C) CEVAP 2011

\section{SUBMISSION STATUS}

Received: January 21, 2011.

Accepted: March 17, 2011.

Abstract published online: March 21, 2011.

Full paper published online: May 31, 2011.

\section{CONFLICTS OF INTEREST}

There is no conflict.

\section{CORRESPONDENCE TO}

KARLA P. O. LUNA, Av. Moraes Rego, 1235, Cidade Universitária, Recife, PE, 50670420, Brazil. Phone: +55 812101 2631. Email: karlaceatox@yahoo.com.br.

\section{REFERENCES}

1. Kasturiratne A, Wickremasinghe AR, de Silva N, Gunawardena, NK, Pathmeswaran, A et al. The global burden of snakebite: a literature analysis and modelling based on regional estimates of envenoming and deaths. PLoS Med. 2008;5(11):218.

2. World Health Organization (WHO) [homepage on the Internet]. Neglected tropical diseases [cited January 2011]. Available from: http://www. who.int/neglected_diseases/diseases/snakebites/ en/index.html.

3. Williams D, Gutiérrez JM, Harrison R, Warrell DA, White J, Winkel K, Gopalakrishnakone, P. The Global Snake Bite Initiative: an antidote for snake bite. Lancet. 2010; 375(9708):89-91.

4. Gutiérrez JM, Williams D, Fan H, Warrell DA. Snakebite envenoming from a global perspective: towards an integrated approach. Toxicon. 2010; 56(7):1223-35.

5. Gutiérrez, JM, Sanz, L, Flores-Díaz, M, Figueroa, $\mathrm{L}$, Madrigal, $\mathrm{M}$, et al. Impact of regional variation in Bothrops asper snake venom on the design of antivenoms: integrating antivenomics and neutralization approaches. J Proteome Res. 2010; 9(11):564-77.

6. Bochner RS, Struchiner CJ. Epidemiologia dos acidentes ofídicos nos últimos 100 anos no Brasil: uma revisão. Cad Saúde Pública. 2003; 19(1):716.

7. Petricevich VL, Teixeira CFP, Tambourghi DV, Gutiérrez JM. Increments in serum cytokine and nitric oxide levels in mice injected with Bothrops asper and Bothrops jararaca snake venom. Toxicon. 2000; 38 1253-66.

8. Meki ARMA, El-Dean ZMM. Serum interleukin$1 \beta$, interleukin- 6 , nitric oxide and $\alpha 1$-antitripsin in scorpion envenomed children. Toxicon. 1998; 36(12):1851-9.

9. Tambourgi DV, dos Santos MC, Furtado M de F, de Freitas MC, da-Silva DW, Kipnis TL. Proinflammatory activities in elapid snake venoms. Br J Pharmacol. 1994;112(3):723-7.

10. Radi RBJS, Beckman JS, Bush KM, Freeman BA. Peroxynitriteoxidation of sulphydryls: the cytotoxic potential of superoxide and nitric oxide. J Biol Chem. 1991;266:4244-50.

11. Hogg N, Darley-Usmar VM, Wilson MT, Moncada S. Production of hydroxyl radicals from the simultaneous generation of superoxide and nitric oxide. Biochem J. 1992;281:419-24.

12. Farsky SH, Walber J, Costa-Cruz M, Cury Y, Teixeira CF. Leukocyte response induced by Bothrops jararaca crude venom: in vivo and in vitro studies. Toxicon. 1997;35(2):185-93.

13. Dias-Da-Silva W, Tambourgi DV, Campos ACMR, Magnoli F, Petricevich VL, Kipnis TL. Complement activation by animal venoms. J Toxicol Toxin Rev. 1995;14(3):375-400.

14. Koh DCI, Armugam A, Jeyaseelan K. Snake venom components and their application in biomedicine. Cell Mol Life Sci. 2006;63(24):303041.

15. White J. Snake venoms and coagulopathy. Toxicon. 2005;45(8):951-67.

16. Kamiguti AS, Cardoso JLC, Theakston RDG, Sano-Martins IS, Hutton RA, Rugman FP, et al. Coagulopathy and hemorrhage in human victims of Bothrops jararaca envenoming in Brazil. Toxicon. 1991;29(8): 961-72.

17. Mandelbaum FR. Isolamento e caracterização de dois fatores hemorrágicos do veneno de Bothrops jararaca [thesis]. São Paulo: Escola Paulista de Medicina;1976.

18. Gutiérrez JM, Bolaños R Arroyo O. Mionecrosis, hemorragia y edema inducidos por el veneno de Bothrops asper en ratón blanco. Toxicon. 1980;18(5-6):603-10.

19. Gutiérrez JM, Romero M, Díaz C, Borkow G, Ovadia M. Isolation and characterization of a metalloproteinase with weak hemorrhagic activity from the venom of the snake Bothrops asper (terciopelo). Toxicon. 1995;33(1)19-29. 
20. Rucavado NA, Núñez J, Gutiérrez JM. Blister formation and skin damage induced by BaP1, a hemorrhagic metalloproteinase from the venom of the snake Bothrops asper. Int J Exp Pathol. 1998;79(4):245-56.

21. Rucavado A, Flores-Sánchez E, Franceschi A, Magalhães A, Gutiérrez JM. Characterization of the local tissue damage induced by LHF-II, a metalloproteinase with weak hemorrhagic activity isolated from Lachesis muta muta snake venom. Toxicon. 1999;37(9):1297-312.

22. Gonçalves LR, Mariano M. Local hemorrhage induced by Bothrops jararaca venom: relationship to neurogenic inflammation. Med Inflamm. 2000;9(2):101-7

23. Meier J, White J. Handbook of clinical toxicology of animal venoms and poisons. Boca Raton: CRC Press; 1995.

24. Ojnuckarin $P$, MahasandanaS, Intragumthornchai T, Sutcharitchan P, Swasdikul D. Prognostic factors of green pit viper bites. Am J Trop Med Hyg. 1998, 58(1):22-5

25. Tallon RW, Koch KL, Barnes SG, Ballard JO. Envenomation coagulopathy from snake bites. $\mathrm{N}$ Engl J Med. 1981;305(2):1347-8.

26. Sano-Martins IS, Santoro ML, Castro SC, Fan HW, Cardoso JL, Theakston RDG. Platelet aggregation in patients bitten by the Brazilian snake Bothrops jararaca. Thromb Res. 1997;87(2):183-9527.

27. Santoro ML, Sano-Martins IS. Platelet dysfunction during Bothrops jararaca snake envenomation in rabbits. Thromb Haemost. 2004;92 (2):369-83.

28. Santoro ML, Sano-Martins IS, Chamone DA. In vivo platelet activation induced by Bothrops jararaca venom in rabbits. Platelets. 1994;5(3):162-70.

29. Maruyama M, Kamiguti AS, Cardoso JL, SanoMartins IS, Chudzinski AM, Santoro ML, et al. Studies on blood coagulation and fibrinolysis in patients bitten by Bothrops jararaca (jararaca). Thromb Haemost. 1990;63(3):449-53.

30. Santoro ML, Sano-Martins IS, Fan HW, Cardoso JL, Theakston RDG, Warrell DA, et al. Haematological evaluation of patients bitten by the jararaca, Bothrops jararaca, in Brazil. Toxicon. 2008;51(8):1440-8.

31. Asano S, Okano A, Ozawa K, Nakahata T, Ishibashi $\mathrm{T}$, Koike $\mathrm{K}$, et al. In vivo effects of recombinant human interleukin-6 in primates: stimulated production of platelets. Blood. 1990;75(8):1602-5.

32. Hill RJ, Warren MK, Levin J. Stimulation of thrombopoiesis in mice by human recombinant interleukin 6. J Clin Invest. 1990,85(4):1242-7.

33. Ishibashi $\mathrm{T}$, Kimura $\mathrm{H}$, Shikama $\mathrm{Y}$, Uchida $\mathrm{T}$, Kariyone S, Hirano $\mathrm{T}$, et al. Interleukin-6 is a potent thrombopoietic factor in vivo in mice.
Blood. 1989;74(4):1241-4.

34. Avila-Aguero ML, Paris MM, Hu S, Peterson PK, Gutiérrez JM, Lomonte B, et al. Systemic cytokine response in children bitten by snakes in Costa Rica. Pediatr Emerg Care. 2001;17(6):425-9.

35. Barraviera B, Lomonte B, Tarkowski A, Hanson LA, Meira DA. Acute-phase reactions including cytokines in patients bitten by Bothrops and Crotalus snakes in Brazil. J Venom Anim Toxins. 1995;1(1):11-22.

36. Lomonte B, Tarkowski A, Hanson LA. Host response to Bothrops asper snake venom. Analysis of edema formation, inflammatory cells, and cytokine release in a mouse model. Inflammation. 1993;17(2):93-105.

37. Smith MJ, Bolam JP. Anti-inflammatory effects of blood platelets in the rat. J Patol. 1979;129(2):6571 .

38. Weyrich AS, Lindemann S, Zimmerman GA. The evolving role of platelets in inflammation. J Thromb Haemost. 2003;1(9):1897-905.

39. Thomas L, Chausson N, Uzan J, Kaidomar S, Vignes R, Plumelle Y, et al. Thrombotic stroke following snake bites by the "Fer-de-Lance" Bothrops lanceolatus in Martinique despite antivenom treatment: a report of three recent cases. Toxicon. 2006;48(1):23-8.

40. Malbranque S, Piercecchi-Marti MD, Thomas L, Barbey C, Courcier D, Bucher B, et al. Fatal diffuse thrombotic microangiopathy after a bite by the "Fer-de-Lance" pit viper (Bothrops lanceolatus) of Martinique. Am J Trop Med Hyg. 2008;78(6):856-61.

41. Numeric P, Moravie V, Didier M, Chatot-Henry D, Cirille S, Bucher B, et al. Multiple cerebral infarctions following a snakebite by Bothrops caribbaeus. Am J Trop Med Hyg. 2002;67(3):2878.

42. Wuster W, Golay P, Warrel D. Synopsis of recent developments in venomous snake systematic, No. 3. Toxicon.1999;37(8):1123-9.

43. Gutiérrez JM, Chaves F, Gene JA, Lomonte B, Camacho Z, Schosinsky K. Myonecrosis induced in mice by a basic myotoxin isolated from the venom of the snake Bothrops nummifer (jumping viper) from Costa Rica. Toxicon. 1989;27(7):73545

44. Brunton LL, Lazo JS, Parker KL, editors. Goodman \& Gilman: as bases farmacológicas da terapêutica. 9th ed. Rio de Janeiro: Mc Graw-Hill; 1996.

45. Moura-da-Silva AM, Desmond H, Laing G, Theakston RDG. Isolation and comparison of myotoxins isolated from venoms of different species of Bothrops snakes. Toxicon. 1991;29(6):713-23. 
46. França FOS, Málaque CMS. Acidente botrópico. In: Cardoso JLC, França FOS, Wen FH, Málaque CMS, Haddad Jr. V, editors. Animais peçonhentos no Brasil: biologia, clínica e terapêutica dos acidentes. São Paulo: Sarvier/FAPESP; 2003.

47. Rocha e Silva M, Beraldo, WT, Rosenfeld G. Bradykinin, a hypotensive and smooth muscle stimulating factor released from plasma globulin by snake venoms and by trypsin. 1949. Am J Physiol. 1949;156(2):261-73.

48. Barros SF, Friedlanskaia I, Petricevich VL, Kpinis TL. Local inflammation, lethality and cytokine release in mice injected with Bothrops atrox venom. Mediators Inflamm. 1998;7(5):339-46.

49. Clissa PB, Lopes-Ferreira M, Della-Casa MS, Farsky SH, Moura-Da-Silva AM. Importance of jararhagin disintegrin-like and cysteine-rich domains in the early events of local inflammatory response. Toxicon. 2006;47(5):591-6.

50. Xavier Da Silva V, Rodrigues MT. Taxonomic revision of the Bothrops neuwiedi complex (Serpentes, Viperidae) with description of a new species. Phyllomedusa. 2008;7(1):45-90.

51. Lopes DS, Baldo C, Oliveira CdeF, Alcântara TM, Oliveira JDD, Goulart LR. Characterization of inflammatory reaction induced by neuwiedase, a P-I metalloproteinase isolated from Bothrops neuwiedi venom. Toxicon. 2009;54(1):42-9.

52. Fernandes CM, Zamuner SR, Zuliani PJ, Rucavado A, Gutiérrez JM, Teixeira CF. Inflammatory effects of $\mathrm{BaP} 1$ a metalloproteinase isolated from Bothrops asper snake venom: leukocyte recruitment and release of cytokines. Toxicon. 2006;47(5)549-59.

53. Costa EP, Clissa PB, Teixeira CF, Moura-DaSilva AM. Importance of metalloproteinases and macrophages in viper snake envenomationinduced local inflammation. Inflammation. 2002;26(1):13-7.

54. Stylianou E, Saklatvala J. Molecules in focus: interleukin-1. Int J Biochem Cell Biol. 1998;30 (1):1075-9.

55. Ebnet K, Vestweber D. Molecular mechanisms that control leukocytes extravasation: the selectins and the chemokines. Histochem Cell Biol. 1999;112(1):1-23.

56. Hopkins SJ. The pathophisiological role of cytokines. Leg Med. 2003;5(1):S45-S57

57. Clissa PB, Laing GD, Theakston RD, Mota I, Taylor MJ, Moura-da-Silva AM. The effect of jararhagin, a metalloproteinase from Bothrops jararaca venom, on pro-inflammatory cytokines released by murine peritoneal adherent cells. Toxicon. 2001;39(10):1567-73.

58. Clissa PB, Lopes-Ferreira M, Della-Casa MS, Farsky SH, Moura-da-Silva AM. Importance of jararhagin disintegrin-like and cysteine-rich domains in the early events of local inflammatory response. Toxicon. 2006;47(5):591-6.

59. Luna KPO, Melo CML, Pascoal VPM, MartinsFilho AO, Pereira VRA. Bothrops erythromelas snake venom induces a proinflammatory response in mice splenocytes. Int J Interf Cytok Mediator Res. 2011;2011(3):9-18.

60. Mossman TR, Coffman RL. TH1 and TH2 cells: different patterns of lymphokine secretion lead to different functional properties. Annu Rev Immunol. 1989;7:145-73

61. Farsky SH, Gonçalves LR, Gutiérrez JM, Correa AP, Rucavado A, Gasque P, et al. Bothrops asper snake venom and its metalloproteinase $\mathrm{BaP} 1$ activate the complement system. Mediators Inflamm. 2000;9(5):213-21.

62. Luna KP, Xavier EM, Pascoal VP, Martins-Filho AO, Pereira VR. Humoral immune response of patients bitten by the snake Bothrops erythromelas. Rev Soc Bras Med Trop. 2010;43(6):731-2.

63. Rodrigues FGP, Kanashiro MM, Petrestki JH, Lemos L, daSilva WD, Kipnis TL. The complement system is involved in acute inflammation but not in the hemorrhage produced by a Bothrops atrox snake venom low molecular mass proteinase. Mol Immunol. 2004;40(16):1149-56.

64. Hawgood BJ. Pioneers of anti-venomous serotherapy: Dr Vital Brazil (1865-1950). Toxicon.1992;30(5-6):573-9.

65. Hawgood BJ. Doctor Albert Calmette 18631933: founder of antivenomous serotherapy and of antituberculous BCG vaccination. Toxicon. 1999;37(9):1241-58

66. Brazil V. Contribuição ao estudo do veneno ofídico: tratamento das mordeduras de cobra. Rev Med São Paulo. 1903;(13):265-78

67. Brazil V. Contribution à l'étude de l'intoxication d’origine ophidienne. Paris: Maloine, 1904.

68. Cardoso DFP. Produção de soro antitoxinas e perspectivas de modernização por técnicas de biologia molecular. In: Cardoso JLC, França FOS, Wen FH, Málaque CMS, Haddad Jr. V, editors. Animais peçonhentos no Brasil: biologia, clínica e terapêutica dos acidentes. São Paulo: Sarvier/ FAPESP; 2003.

69. Warrell DA. Geographical intraspecies variation in the clinical manifestation of envenoming by snakes. In: Thorpe RS, Wuster W, Malhorta A, editors. Venomous snakes: ecology, evolution and snake bites. Oxford: Claredon Press; 1997. p. 189-203.

70. Gutiérrez JM, Lomonte B, León G, Alape-Girón A, Flores-Díaz M, Sanz L, et al. Snake venomics and antivenomics: proteomic tools in the design and control of antivenoms for the treatment of 
snakebite envenoming. J Proteomics. 2009; 72 (2):165-82.

71. Calvete JJ, Sanz L, Angulo Y, Lomonte B, Gutiérrez JM. Venoms, venomics, antivenomics. FEBS Lett. 2009;583(11):1736-43.

72. Alape-Girón A, Sanz L, Escolano J, Flores-Díaz M, Madrigal M, Sasa M, et al. Snake venomics of the lancehead pitviper Bothrops asper: geographic, individual, and ontogenetic variations. J Proteome Res. 2008;7(8):3556-71.

73. Nuñez V, Cid P, Lomonte B, Gutiérrez JM, Calvete JJ, et al. Snake venomics and antivenomics of Bothrops atrox venoms from Colombia and the Amazon regions of Brazil, Peru and Ecuador suggest the occurrence of geographic variation of venom phenotype by a trend towards paedomorphism. J Proteomics. 2009;73(1):57-78.

74. Gutiérrez JM, Sanz L, Flores-Días M, Figueroa L, Madrigal M, Herrera $M$ et al. Impact of regional variation in Bothrops asper snake venom on the design of antivenoms: integrating antivenomics and neutralization approaches. J Proteomes Res. 2010;9(1):564-77.
75. Arce-Estrada V, Azofeifa-Cordero G, Estrada R, Alape-Girón A, Flores-Díaz M. Neutralization of venom-induced hemorrhage by equine antibodies raised by immunization with a plasmid encoding a novel P-II metalloproteinase from the lancehead pitviper Bothrops asper. Vaccine. 2009;27(3):460-6.

76. Azofeifa-Cordero G, Arce-Estrada V, FloresDíaz M, Alape-Girón A. Immunization with cDNA of a novel P-III type metalloproteinase from the rattlesnake Crotalus durissus durissus elicits antibodies which neutralize $69 \%$ of the hemorrhage induced by the whole venom. Toxicon. 2008;52(2):302-8.

77. Wagstaff SC, Laing GD, Theakston RD, Papaspyridis C, Harrison RA, et al. Bioinformatics and multiepitope DNA immunization to design rational snake antivenom. PLoS Med. 2006;3(6):e184. 